\title{
Tuberculosis miliar secundaria a instilación endovesical de BCG
}

\author{
Fernández Jiménez-Ortiz H, Gómez Marco JJ, Rojo Zamanillo I, Fernández Fernández E. \\ Centro de Salud Las Calesas. Madrid. \\ Actas Urol Esp. 2007;31(7):783-784
}

\section{RESUMEN}

TUBERCULOSIS MILIAR SECUNDARIA A INSTILACIÓN ENDOVESICAL DE BCG

La instilación endovesical con bacilo de Calmette-Guerin es el tratamiento de elección para el carcinoma superficial e in situ de vejiga. En raras ocasiones presenta complicaciones graves que deben ser tenidas en cuenta. A continuación presentamos un caso de reactivación endógena de tuberculosis miliar secundaria a dicho tratamiento.

Palabras clave: Neoplasias vesicales. Vacuna BCG. Tuberculosis. Efectos adversos.

\section{ABSTRACT}

MILIARY TUBERCULOSIS IN A PATIENT TREATED WITH BCG INTRAVESICAL INSTILLATION

Intravesical instillation of bacillus Calmette-Guérin is the elective treatment for trnasitional cell and in situ bladder carcinoma. Severe complications occur very seldom but must be known and promptly recognized. We present a case of miliary tuberculosis reactivation secondary to the mentioned treatment.

Keywords: Bladder neoplasms. BCG vaccine. Adverse effects.

$\mathrm{T}$ ras leer la interesante carta al editor de Pego et al. ${ }^{1}$ sobre complicaciones del tratamiento con instilación endovesical del bacilo de Calmette-Guerin (BCG) para el carcinoma de vejiga, se nos presentó el caso de otra complicación infrecuente del mismo. La instilación de BCG endovesical se trata del primer tratamiento inmunitario celular con actividad antitumoral demostrada $^{2}$, y todavía es hoy en día el tratamiento de elección para el carcinoma superficial de células transicionales y para el carcinoma in situ de vejiga ${ }^{3}$. La frecuencia de complicaciones sistémicas oscila en torno al $3-55 \% \%^{4}$, la mayoría banales, que incluyen síndrome miccional, fiebre, malestar general, astenia, artralgias, artritis. Complicaciones más graves pueden ser vitíligo ${ }^{5}$, hepatitis, neumonitis, sepsis, sindrome de Reiter $^{1}$, reactivación endógena de tuberculosis (TBC) latente, etc... Las complicaciones pulmonares suponen el $1-3 \%^{3}$, algunas pueden ser asin- tomáticas y se han descrito cinco formas; neumonitis intersticial, empiema, daño alveolar difuso, neumonía consolidativa con o sin cavitación y TBC miliar ${ }^{4}$. Se han descrito tasas de abandono de hasta $7 \%$ debido a efectos adversos ${ }^{1}$.

Presentamos un caso de TBC miliar por reactivación endógena tras tratamiento con BCG endovesical para un carcinoma superficial de vejiga.

\section{CASO CLÍNICO}

Varón de 72 años con antecedentes personales de hipertensión arterial, enfermedad pulmonar obstructiva crónica, exfumador y diagnosticado de carcinoma papilar urotelial de vejiga (T1G2). Se realizó resección transuretral del tumor y 3 semanas después se inició tratamiento con ciclo largo de instilaciones endovesicales de BCG (cepa Connaught, $10^{9}$ unidades formadoras de colonias por dosis) administradas semanalmente. 
Tras recibir 3 sesiones acude a urgencias por malestar general y fiebre $\left(38,5^{\circ}\right)$ de diez días de evolución. No presentaba síndrome miccional ni otra sintomatología. La exploración física resultó anodina con auscultación pulmonar normal, puño percusión renal bilateral negativa y próstata no dolorosa ni congestiva, tamaño II/IV y consistencia adenomatosa. El hemograma presentó ligera leucocitosis $\sin$ neutrofilia (leucocitos 12100 y 63,7\% neutrófilos). Urocultivos y hemocultivos fueron estériles y la búsqueda de bacilos ácido alcohol resistentes en orina fue infructuosa. La radiografía de tórax mostró afectación bilateral y difusa de pequeños nódulos milimétricos con adenopatías gruesas calcificadas, compatibles con TBC miliar. En la tomografía axial computerizada (TAC) se observaron adenopatías groseras calcificadas en hilio y ligamento pulmonar derechos y afectación bilateral y difusa parenquimatosa de pequeños nódulos milimétricos que afectan todos los campos pulmonares. El paciente ingresó y recibió tratamiento con isoniazida, rifampicina y etambutol. El paciente mejoró de su estado general por lo que fue dado de alta y seguido ambulatoriamente. Durante el seguimiento no se presentaron efectos adversos de la medicación ni nuevos episodios febriles $u$ otra sintomatología. El tratamiento antituberculoso se pautó durante 6 meses interrumpiéndose las instilaciones de BCG. En el TAC de control a los dos meses se observó disminución del tamaño de las adenopatías así como disminución en el número de nódulos, con desaparición completa en algunos segmentos pulmonares.

\section{DISCUSIÓN Y CONCLUSIONES}

El diagnóstico de presunción es TBC miliar secundaria a instilaciones endovesicales con BCG, complicación infrecuente $(<1 \%)$ pero descrita en la literatura ${ }^{3,4}$ y potencialmente grave. El diagnóstico definitivo de TBC miliar requiere la detección microbiológica de la mycobacteria en cultivo de tejido infectado ${ }^{1}$, sin embargo en este caso no se realizó biopsia pulmonar dado el cuadro clínico y hallazgos radiológicos compatibles, así como la evolución favorable. Se han relacionado con mayor probabilidad de presentar diseminación miliar tras el tratamiento la sobredosificación por error así como técnica de instilación incorrecta. Hechos que no se constataron en nuestro paciente. Koga et al. ${ }^{4}$ encontraron mayor probabilidad de efectos adversos graves con dosis de $80 \mathrm{mg}$ que con dosis de $40 \mathrm{mg}$ de BCG, sin embargo su estudio es demasiado pequeño para extraer conclusiones por lo que son necesarios más estudios que determinen cual es la dosis que presenta mejor relación riesgo beneficio.

No se realizó estudio de contactos pero hasta la fecha no se conoce ninguno contagiado. Tampoco consta tratamiento o enfermedad médica que condicione inmunosupresión por lo que otras fuentes del contagio de TBC son poco probables.

Finalmente, debemos concluir que la terapia con BCG se considera segura debido a la baja frecuencia de complicaciones que presenta. Ante un paciente que recibe terapia con BCG y presenta un cuadro febril sin foco se debe sospechar y descartar con hemocultivos, BAAR en orina y esputo y radiografía de tórax esta rara complicación.

\section{REFERENCIAS}

1. Pego Pego JM, Lamas C, Hernández I, Suso J. Síndrome de Reiter recidivante después de inmunoterapia con Bacillus Calmette-Guèrin para el carcinoma de vejiga. Med Clin (Barc) 2003;121(9):356-359.

2. Ribas A, Ribas-Mundó M. Vacunas antitumorales en desarrollo clínico. Med Clin (Barc). 2002;118(12):472-476.

3. Iantorno R, Nicolai M, Storto ML, Ciccotosto C, Cipollone G, Mastroprimiano G, et al. Miliary tuberculosis of the lung in a patient treated with bacillus Calmette-Guèrin for superficial bladder cancer. J Urol. 1998;159(5):1639-1640.

4. Koga H, Kuroda M, Kudo S, Yamaguchi A, Usami M, Suzuki $\mathrm{T}$, et al. Adverse drug reactions of intravesical bacillus Calmette-Guèrin instillation and risk factors of the development of adverse drug reactions in superficial cancer and carcinoma in situ of the bladder. Int J Urol. 2005;12(2):145-151.

5. Beisland C, Holsen DS. Vitiligo and autoimmune side-effect of intravesical bacillus Calmette-Guerin intillation?. Scand J Urol Nephrol. 2004;38(2):182-183.

6. Altet Gómez MN, Alcaide Megías J, Jiménez Fuentes MA, Milá Augé C, Solsona Peiró J, de Souza-Galvão ML, Romero Cabestany MA, Barrios Gutiérrez M. La vacuna BCG: la controversia continua. Vacunas 2003;4:95-101.

7. Guía clínica en formato electrónico PDF, Diagnóstico de la tuberculosis. Caminero Luna J, Casal Roman M, Auxina Ruiz V, Pina Gutierrez JM, Sauret Valet J. \{Consultado el 11/01/2006\} Disponible en: http://www.separ.es/publicaciones/normativas.

Correspondencia autor: Dr. H. Fernández Jiménez-Ortiz

Centro de Salud Las Calesas. Madrid

E-mail autor: hectorestaki@yahoo.es

Información artículo - Nota clínica

Trabajo recibido: mayo 2006

Trabajo aceptado: diciembre 2006 